\title{
Molecular and Cellular Phenotypic Profiles of Gastric Noninvasive Neoplasia
}

\author{
Zhe Jin, Gen Tamura, Teiichiro Honda, and Teiichi Motoyama \\ Department of Pathology, Yamagata University School of Medicine, Yamagata, Japan
}

SUMMARY: According to the Padova international classification, 52 gastric noninvasive neoplasias (NIN) were classified as follows: 20 low-grade NIN (L-NIN); 9 high-grade NIN including suspicion for carcinoma without invasion (H-NIN); and 23 high-grade NIN including carcinoma without invasion (Ca-NIN). The molecular and cellular phenotypic profiles were investigated and compared. The APC gene was mutated in seven (35\%) L-NIN, two (22\%) H-NIN, and two (9\%) Ca-NIN tumors; APC mutations were significantly more frequent in L-NIN compared with Ca-NIN tumors $(p<0.05)$. Mutations of the $p 53$ gene were found in five $(22 \%)$ Ca-NIN tumors but were not observed in L-NIN or H-NIN tumors $(p<0.05)$. Loss of heterozygosity involving at least one chromosomal locus was detected in 14 (61\%) Ca-NIN tumors but was not detected in L-NIN or H-NIN tumors. High-frequency microsatellite instability (MSI-H) was detected in one (5\%) L-NIN tumor and in six (26\%) Ca-NIN tumors. The frequencies of loss of heterozygosity and MSI-H were significantly higher in Ca-NIN than in L-NIN or H-NIN tumors $(p<0.05)$. Nuclear accumulation of p53 protein was detected in no L-NIN tumors, 1 (11\%) H-NIN tumor, and 10 (44\%) Ca-NIN tumors $(p$ $<0.01)$. All tumors with loss of hMLH1 expression exhibited MSI-H $(p<0.01)$. Cellular phenotypic analysis revealed that seven (35\%) L-NIN tumors and one (4\%) Ca-NIN tumor had complete-type intestinal metaplastic phenotype and that one (5\%) L-NIN tumor and one (4\%) Ca-NIN tumor had a gastric foveolar epithelial phenotype, whereas the remaining tumors exhibited an ordinary phenotype. Thus, the complete-type intestinal metaplastic phenotype was more characteristic of L-NIN tumors than of $\mathrm{H}-\mathrm{NIN}$ or Ca-NIN tumors $(p<0.01)$. In summary, the Padova international classification correlated with both the molecular and cellular phenotypic profiles. In practice, p53 and hMLH1 immunohistochemistry discriminated Ca-NIN from L-NIN and H-NIN tumors. (Lab Invest 2002, 82:1637-1645).

$O$ wing to improvements in both radiology and endoscopic technologies and to the popularization of mass screening, more than half of the surgically resected gastric cancers in Japan are found at early stages (Isozaki et al, 1999; Sasako, 2000). In addition, endoscopic mucosal resection has become common in cases of gastric noninvasive neoplasia (Isozaki et al, 1999; Sasako, 2000). The therapeutic decision depends on several clinicopathologic factors, including macroscopic appearance, tumor size, and histopathologic diagnosis. Although an accurate histopathologic diagnosis is essential, discrepancies have been recognized in the diagnosis of carcinoma versus dysplasia (or adenoma) between pathologists and, in particular, between Western and Japanese pathologists (Riddell and Iwafuchi, 1998; Schlemper et al, 1997, 2000). Although objective diagnostic markers are desirable, the results of genetic analyses of gastric noninvasive neoplasia also seem to be inconsistent among pathologists. Thus, the malignant potential of gastric adenoma continues to be controversial mainly because of the differences in histopathologic criteria as described above (Tamura et al, 1996a). Therefore, standardization of the histopathologic criteria for gas-

\section{DOI: 10.1097/01.LAB.0000041712.58604.CC}

Received July 25, 2002.

Address reprint requests to: Dr. Gen Tamura, Department of Pathology, Yamagata University School of Medicine, 2-2-2 Iida-nishi, Yamagata 990-9585, Japan.E-mail: gtamura@med.id.yamagata-u.ac.jp tric noninvasive neoplasia is required to resolve these discrepancies. Clinicopathologic observations have suggested that malignant transformation of gastric adenoma occurs infrequently (Kamiya et al, 1982; Nakamura et al, 1988). Furthermore, although some gastric adenomas disappear spontaneously (Kamiya et al, 1982) or with eradication of Helicobacter pylori (our unpublished data), no useful markers are available to predict this outcome. Also, because the sequential accumulation of genetic alterations that are characteristic of the colorectal adenoma-carcinoma sequence do not occur in the progression from gastric adenoma to adenocarcinoma, the critical genetic changes that lead to malignant transformation of gastric adenoma are unknown (Maesawa et al, 1995). A worldwide histopathologic classification (the Padova international classification) has recently been proposed for gastric noninvasive neoplasia (Rugge et al, 2000), and we have attempted to characterize the molecular and cellular phenotypic features of gastric noninvasive neoplasia with tubular differentiation according to this classification.

In the present study, 52 gastric noninvasive tumors were classified into three categories according to the Padova international classification (Rugge et al, 2000). Mutations of the APC and p53 genes, microsatellite alterations including loss of heterozygosity $(\mathrm{LOH})$ and microsatellite instability (MSI), expression of p53 and hMLH1 proteins, and the cellular phenotype (Ohmura et al, 2000) were analyzed. 


\section{Results}

\section{Mutations of APC and p53}

The APC gene was mutated in seven (35\%) cases of low-grade noninvasive neoplasia (L-NIN), two (22\%) cases of high-grade noninvasive neoplasia including suspicion for carcinoma without invasion (H-NIN), and two $(9 \%)$ cases of high-grade noninvasive neoplasia including carcinoma without invasion (Ca-NIN) (Table 1, Fig. 2). Sequencing analysis of the mobility-shift bands revealed that all the mutations were frameshift mutations (Table 2). APC mutations were more frequently observed in L-NIN than in Ca-NIN tumors $(p<$ 0.05). Mutation of the $p 53$ gene was found in five (22\%) Ca-NIN tumors but was not observed in L-NIN or H-NIN tumors $(p<0.05)$ (Table 1 , Fig. 3). Four of the five $p 53$ gene mutations were missense and the other was a nonsense mutation (Table 2).

\section{Microsatellite Alterations}

$\mathrm{LOH}$ involving at least 1 chromosomal locus was detected in 14 (61\%) Ca-NIN cases but was not seen in L-NIN or H-NIN cases (Table 1, Fig. 4). Highfrequency microsatellite instability $(\mathrm{MSI}-\mathrm{H})$ was detected in one (5\%) L-NIN and six (26\%) Ca-NIN tumors but in no H-NIN tumors (Table 1, Fig. 4). The two foveolar epithelial phenotype (foveolar-type) tumors (one L-NIN and one Ca-NIN) exhibited MSI-H (Table 1). The frequencies of both $\mathrm{LOH}$ and $\mathrm{MSI}-\mathrm{H}$ were significantly higher in $\mathrm{Ca}-\mathrm{NIN}$ tumors than in L-NIN or H-NIN tumors ( $p<0.05)$.

\section{p53 and hMLH1 Protein Expression}

Nuclear accumulation of p53 protein was observed in $1(11 \%) \mathrm{H}-\mathrm{NIN}$ and 10 (44\%) Ca-NIN tumors but in no L-NIN tumors (Table 1, Fig. 5A). For Ca-NIN tumors, significantly higher rates of nuclear accumulation of p53 were observed in cases with mutation of the p53 gene and/or LOH on chromosome 17p (80\%; 8 of 10) than in cases without these features $(18 \% ; 2$ of 11) ( $p$ $<0.01)$. Loss of hMLH1 expression was in complete concordance with MSI-H $(p<0.01)$ (Table 1, Fig. 5B). The relationship between the histopathologic classification and expression patterns of p53 and hMLH1 is summarized in Table 3.

\section{Cellular Phenotype}

The complete-type intestinal metaplastic phenotype (CIM-type) was observed in seven (35\%) L-NIN tumors and one (4\%) Ca-NIN tumor, whereas one $(5 \%)$ L-NIN tumor and one (4\%) Ca-NIN tumor showed the gastric foveolar type. The remaining tumors were classified as ordinary phenotype (Table 1, Fig. 6). CIM-type was associated with L-NIN rather than $\mathrm{H}-\mathrm{NIN}$ and Ca-NIN tumors $(p<0.01)$.

\section{Discussion}

It is acknowledged that discrepancies exist in the histopathologic criteria for gastric noninvasive neopla- sia. For instance, there is disagreement between Western and Japanese pathologists (Riddell and Iwafuchi, 1998; Schlemper et al, 1997, 2000), and even between Japanese pathologists (Tamura et al, 1996a), as to the definition of dysplasia (or adenoma) versus (well-differentiated tubular) adenocarcinoma. Carcinoma is diagnosed by virtue of the tumor's structural and cytologic features in Japan but by evidence of invasion in the Western hemisphere (Riddell and Iwafuchi, 1998; Schlemper et al, 1997). It is likely that because of these differences in histopathologic criteria, the results of molecular analyses of gastric neoplasia have also shown considerable disparity. Although $A P C$ mutations are reported to be frequent $(41 \% ; 7 / 17)$ in very well-differentiated adenocarcinoma, as determined by World Health Organization criteria (Nakatsuru et al, 1992), recent evidence suggests that $A P C$ mutations are generally rare and account for less than $10 \%$ of cases of differentiated adenocarcinoma of the stomach (Horii et al, 1992; Ogasawara et al, 1994; Powell et al, 1996). Because APC mutations are characteristic of gastric adenoma (Tamura, 1996), it is possible that some cases that were classified as "very well-differentiated adenocarcinoma" might have been diagnosed as "adenoma" by other pathologists. The reported frequencies of other genetic alterations observed in gastric adenoma/dysplasia have also varied widely. Mutation of the $p 53$ gene or overexpression of p53 protein have been reported to occur in 0\% to 30\% (Craanen et al, 1995; Joypaul et al, 1993; Kyokane et al, 1998; Tohdo et al, 1993), MSI in 4\% to $42 \%$ (Semba et al, 1996; Tamura et al, 1996b), and LOH in 11\% to $87 \%$ (Kim et al, 2001; Tamura et al, 1996b) of cases of gastric adenoma/dysplasia.

In the study presented here, a panel of 52 gastric noninvasive tumors was divided into three categories: $20 \mathrm{~L}-\mathrm{NIN}$ tumors, $9 \mathrm{H}-\mathrm{NIN}$ tumors, and $23 \mathrm{Ca}-\mathrm{NIN}$ tumors, according to the Padova international classification (Rugge et al, 2000). APC mutations were more frequently observed in L-NIN tumors when compared with Ca-NIN tumors ( $p<0.05$ ); $35 \%$ of L-NIN tumors exhibited mutations of the APC gene compared with $22 \%$ of $\mathrm{H}-\mathrm{NIN}$ and $9 \%$ of Ca-NIN tumors. At least two explanations can be proposed. First, few L-NIN tumors progress to become $\mathrm{Ca}-\mathrm{NIN}$, because $A P C$ gene mutations were significantly less frequent in $\mathrm{Ca}-\mathrm{NIN}$ than in L-NIN tumors. If the majority of Ca-NIN cases evolved from L-NIN, then the incidence of $A P C$ gene mutations in Ca-NIN tumors should be equal to or greater than that observed in L-NIN tumors. This result is in accord with clinicopathologic observations in which malignant transformation was observed in $11 \%$ $(9 / 85)$ of gastric adenomas during an average follow-up of 49 months, whereas carcinoma in adenoma was seen in 3.5\% (10/283) of gastric adenomas (Kamiya et al, 1982; Nakamura et al, 1988). The concept that L-NIN rarely evolves to $\mathrm{Ca}-\mathrm{NIN}$ has been proposed previously (Tamura, 1996). A second explanation is that although a significant proportion of L-NIN cases may progress to Ca-NIN via H-NIN, because of the lower incidence of L-NIN as compared 
Table 1. Clinicopathologic and Molecular Characteristics of Gastric Noninvasive Neoplasia

\begin{tabular}{|c|c|c|c|c|c|c|c|c|c|c|c|}
\hline \multirow[b]{2}{*}{ Case no. ${ }^{a}$} & \multirow[b]{2}{*}{ Age } & \multirow[b]{2}{*}{$\operatorname{Sex}^{b}$} & \multirow{2}{*}{$\begin{array}{c}\text { Size } \\
(\mathrm{mm})\end{array}$} & \multirow{2}{*}{$\begin{array}{l}\text { Macroscopic } \\
\text { type }^{c}\end{array}$} & \multirow{2}{*}{$\begin{array}{c}\text { Cellular } \\
\text { phenotype }^{d}\end{array}$} & \multicolumn{2}{|c|}{ Immunostaining $^{e}$} & \multicolumn{2}{|c|}{ MS alterations ${ }^{f}$} & \multicolumn{2}{|c|}{ Mutation ${ }^{h}$} \\
\hline & & & & & & p53 & hMLH1 & MSI & $\mathrm{LOH}$ & $p 53$ & $A P C$ \\
\hline \multicolumn{12}{|l|}{ L-NIN } \\
\hline 1 & 64 & M & 11 & II a & Ordinary & - & + & MSS & $-(0 / 8)^{g}$ & - & - \\
\hline 2 & 73 & $M$ & 16 & II a & Foveolar & - & - & MSI-H & $-(0 / 3)$ & - & - \\
\hline 3 & 63 & $M$ & 7 & II a & CIM & - & + & MSS & $-(0 / 10)$ & - & - \\
\hline 4 & 55 & $M$ & 6 & II a & Ordinary & - & + & MSS & $-(0 / 7)$ & - & + \\
\hline 5 & 74 & M & 12 & II a & Ordinary & - & + & MSS & $-(0 / 7)$ & - & + \\
\hline 6 & 61 & $M$ & 5 & II C & Ordinary & - & + & MSS & $-(0 / 9)$ & - & + \\
\hline 7 & 67 & $M$ & 4 & II a & CIM & - & + & MSS & $-(0 / 6)$ & - & - \\
\hline 8 & 65 & M & 4 & II a & Ordinary & - & + & MSS & $-(0 / 8)$ & - & - \\
\hline 9 & 71 & M & 10 & I & Ordinary & - & + & MSS & $-(0 / 12)$ & - & + \\
\hline 10 & 70 & $M$ & 13 & II a & CIM & - & + & MSS & $-(0 / 10)$ & - & + \\
\hline 11 & 80 & $M$ & 4 & II a & CIM & - & + & MSS & $-(0 / 8)$ & - & + \\
\hline 12 & 69 & M & 6 & II a & CIM & - & + & MSS & $-(0 / 9)$ & - & - \\
\hline 13 & 72 & $\mathrm{~F}$ & 3 & II a & Ordinary & - & + & MSS & $-(0 / 7)$ & - & - \\
\hline 14 & 67 & $M$ & 25 & $\|\mathrm{a}+\| \mathrm{c}$ & Ordinary & - & + & MSS & $-(0 / 9)$ & - & - \\
\hline 15 & 64 & $M$ & 6 & II a & CIM & - & + & MSS & $-(0 / 9)$ & - & - \\
\hline 16 & 75 & $\mathrm{~F}$ & 3 & II a & Ordinary & - & + & MSS & $-(0 / 7)$ & - & - \\
\hline 17 & 67 & $M$ & 4 & II a & CIM & - & + & MSS & $-(0 / 6)$ & - & - \\
\hline 18 & 77 & $M$ & 5 & II a & Ordinary & - & + & MSS & $-(0 / 8)$ & - & - \\
\hline 19 & 52 & $M$ & 37 & $\|\mathrm{a}+\| \mathrm{c}$ & Ordinary & - & + & MSS & $-(0 / 9)$ & - & + \\
\hline 20 & 56 & $\mathrm{~F}$ & 32 & $\|\mathrm{c}+\| \mathrm{a}$ & Ordinary & - & + & MSS & $-(0 / 10)$ & - & - \\
\hline \multicolumn{12}{|l|}{ H-NIN } \\
\hline 21 & 80 & $M$ & 33 & II a & Ordinary & - & + & MSS & $-(0 / 10)$ & - & - \\
\hline 22 & 53 & $M$ & 23 & II C & Ordinary & - & + & MSS & $-(0 / 6)$ & - & - \\
\hline 23 & 68 & $\mathrm{~F}$ & 16 & II C & Ordinary & - & + & MSS & $-(0 / 11)$ & - & - \\
\hline 24 & 78 & $M$ & 30 & II C & Ordinary & - & + & MSS & $-(0 / 9)$ & - & - \\
\hline 25 & 75 & $M$ & 10 & II a & Ordinary & - & + & MSS & $-(0 / 11)$ & - & - \\
\hline 26 & 74 & $M$ & 7 & II a & Ordinary & + & + & MSS & $-(0 / 7)$ & - & - \\
\hline 27 & 55 & $\mathrm{~F}$ & 13 & II C & Ordinary & - & + & MSS & $-(0 / 8)$ & - & + \\
\hline 28 & 74 & $M$ & 10 & $\|c+\| a$ & Ordinary & - & + & MSS & $-(0 / 7)$ & - & + \\
\hline 29 & 63 & $M$ & 26 & $\|\mathrm{a}+\| \mathrm{c}$ & Ordinary & - & + & MSI-L & $-(0 / 6)$ & - & - \\
\hline \multicolumn{12}{|l|}{ Ca-NIN } \\
\hline 30 & 73 & $M$ & 18 & II C & Ordinary & + & + & MSS & $+(1 / 7)$ & - & - \\
\hline 31 & 76 & $M$ & 14 & II a & Foveolar & - & - & MSI-H & $-(0 / 3)$ & - & - \\
\hline 32 & 59 & $M$ & 53 & I & Ordinary & - & + & MSS & $-(0 / 7)$ & + & - \\
\hline 33 & 68 & $M$ & 13.5 & II a & Ordinary & + & + & MSS & $-(0 / 8)$ & - & - \\
\hline 34 & 66 & $M$ & 10.5 & II a & Ordinary & - & - & MSI-H & $-(0 / 4)$ & - & - \\
\hline 35 & 75 & $\mathrm{~F}$ & 17 & II a & Ordinary & - & - & MSI-H & $+(1 / 3)$ & - & - \\
\hline 36 & 49 & $M$ & 16 & II C & Ordinary & + & + & MSS & $\begin{array}{l}+(3 / 7) \\
\end{array}$ & + & - \\
\hline 37 & 80 & $\mathrm{~F}$ & 19 & II C & Ordinary & - & - & MSI-H & $-(0 / 3)$ & - & - \\
\hline 38 & 64 & $M$ & 28 & 1 & Ordinary & + & + & MSS & $+(3 / 9)$ & + & - \\
\hline 39 & 50 & $M$ & 15 & II C & Ordinary & + & + & MSS & $\begin{array}{l}+(1 / 9) \\
+(1 / 4)\end{array}$ & - & + \\
\hline 40 & 69 & $\mathrm{~F}$ & 19 & II C & Ordinary & - & - & MSI-H & $-(0 / 1)$ & - & - \\
\hline 41 & 57 & $M$ & 19 & II C & Ordinary & + & + & MSS & $+(1 / 5)$ & - & - \\
\hline 42 & 75 & $\mathrm{~F}$ & 16 & II C & Ordinary & - & + & MSS & $\begin{array}{l}+(3 / 8) \\
\end{array}$ & - & - \\
\hline 43 & 64 & $M$ & 25 & $\| \mathrm{C}$ & Ordinary & - & + & MSS & $-(0 / 5)$ & - & - \\
\hline 44 & 66 & $M$ & 38 & $1+\| \mathrm{a}$ & Ordinary & + & + & MSI-L & $+(2 / 8)$ & - & - \\
\hline 45 & 82 & $\mathrm{~F}$ & 35 & $\|\mathrm{a}+\| \mathrm{c}$ & Ordinary & + & + & MSS & $-(0 / 7)$ & + & - \\
\hline 46 & 64 & $\mathrm{~F}$ & 28 & II C & CIM & - & + & MSS & $+(2 / 6)$ & - & + \\
\hline 47 & 81 & $\mathrm{~F}$ & 64 & $\|\mathrm{a}+\| \mathrm{c}$ & Ordinary & - & + & MSI-L & $\begin{array}{l}+(1 / 6) \\
+(1 / 6)\end{array}$ & - & - \\
\hline 48 & 73 & $M$ & 41 & $\|c+\| a$ & Ordinary & - & + & MSS & $\begin{array}{l}+(3 / 9) \\
+\end{array}$ & + & - \\
\hline 49 & 47 & $M$ & 36 & II $\mathrm{C}$ & Ordinary & - & + & MSS & $\begin{array}{l}\text { +(1/6) } \\
+(1 / 4)\end{array}$ & - & - \\
\hline 50 & 52 & $M$ & 19 & $\|c+\| a$ & Ordinary & + & + & MSS & $+(1 / 7)$ & - & - \\
\hline 51 & 70 & $M$ & 38 & $\|c+\| a$ & Ordinary & + & + & MSI-L & $+(2 / 7)$ & - & - \\
\hline 52 & 77 & $\mathrm{~F}$ & 38 & $\|\mathrm{a}+\| \mathrm{c}$ & Ordinary & - & - & MSI-H & $-(0 / 3)$ & - & - \\
\hline
\end{tabular}

a L-NIN, low-grade noninvasive neoplasia; H-NIN, high-grade noninvasive neoplasia including suspicion for carcinoma without invasion; Ca-NIN, high-grade noninvasive neoplasia including carcinoma without invasion.

${ }^{b} \mathrm{M}$, male; F, female.

${ }^{c}$ I, protruding-type; II a, superficial elevated-type; II c, depressed-type; II a + II c, predominantly raised with central depression-type; II c + II a, raised with predominance of central depression-type.

${ }^{d}$ Foveolar, gastric foveolar epithelial phenotype; ordinary, ordinary phenotype; CIM, complete intestinal metaplasitic phenotype.

$e_{-}$, negative; +, positive.

${ }^{f}$ MS, microsatellite; MSS, microsatellite stable; MSI-L, low frequency microsatellite instability; MSI-H, high frequency microsatellite instability. LOH: Ioss of heterozygosity; -, LOH absent; +, LOH present

${ }^{g}$ Number of markers showed $\mathrm{LOH} /$ number of informative markers.

${ }^{h}-$, mutation absent; + , mutation present. 


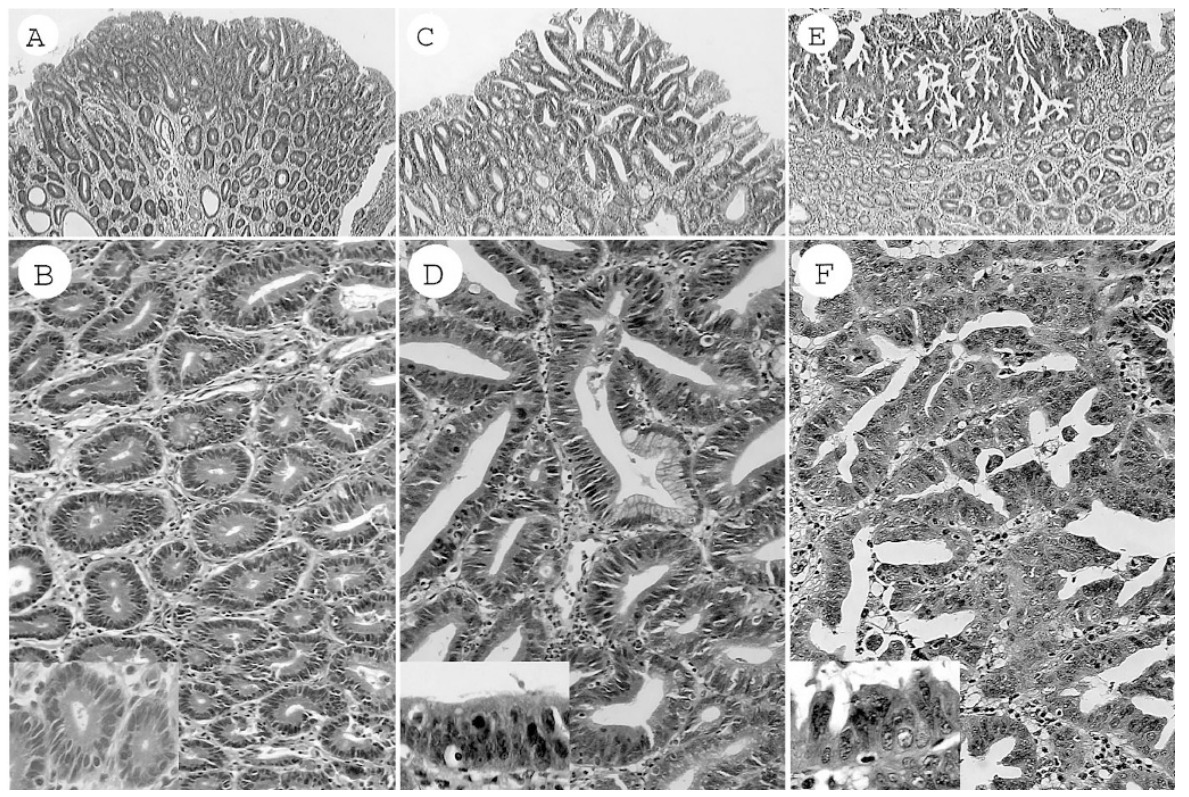

\section{Figure 1.}

Typical morphologic features of the gastric noninvasive neoplasia. A, Low-grade noninvasive neoplasia (L-NIN) (case 4, original magnification, $\times 40)$. B, Nuclei are basally oriented and show slight hyperchromatism and pseudostratification. Glandular structures are regular in arrangement (case 4 , original magnification, $\times 200$; inset, $\times 400$ ). C, High-grade noninvasive neoplasia including suspicion for carcinoma without invasion (H-NIN) (case 28 , original magnification, $\times 40)$. D, Nuclei are variable in size and slightly enlarged and show moderate hyperchromatism and pseudostratification. Glandular structures are irregular in arrangement and show variable size and shape (case 28 , original magnification, $\times 200$; inset, $\times 400$ ). E, High-grade noninvasive neoplasia including carcinoma without invasion (Ca-NIN) (case 51 , original magnification, $\times 40$ ). F, Nuclei are round, vesicular, and variable in size. Glandular structures show variable size and shape with complex budding and branching (case 51 , original magnification, $\times 200$; inset, $\times 400$ ).

with the incidence of Ca-NIN (or, in other words, the frequent de novo development of $\mathrm{Ca}-\mathrm{NIN}$ ), the observed frequency of $A P C$ gene mutation may remain relatively low in Ca-NIN tumors. Thus in the latter situation, $A P C$ gene mutation may function as a marker of malignant transformation of gastric adenoma. A follow-up study of $A P C$ gene mutation in L-NIN and H-NIN cases is underway at present to resolve this issue. Of relevance, in this study we observed no evidence for the sequential accumulation of genetic alterations characteristic of colorectal adenoma-carcinoma sequence, including mutation of the $A P C$ and $p 53$ genes, between L-NIN, H-NIN, and Ca-NIN tumors. Neither of the two Ca-NIN tumors with $A P C$ gene mutations had detectable mutations of $p 53$. In addition, the absence of or rarity of $K$-ras gene mutations in gastric adenocarcinoma has been the subject of a number of previous reports (Endoh et al, 2000a; Maesawa et al, 1995; Ranzani et al, 1993).

Other genetic alterations may also be critical in the malignant transformation of L-NIN tumors with APC mutations, because LOH of several chromosomal loci was present in Ca-NIN cases that demonstrated genetic alterations of the $A P C$ gene. In contrast to the findings of $A P C$ gene analysis, mutation/overexpression of $p 53$ and microsatellite alterations (MSI-H and $\mathrm{LOH})$ were very rare $(3 \%)$ in both L-NIN and H-NIN tumors, whereas they were observed at a frequency of $55 \%$ (12/22) and 82\% (18/22), respectively, in Ca-NIN tumors. Of interest, the sole L-NIN tumor that displayed MSI-H was a foveolar-type tumor. This histologic type of tumor generally exhibits the mutator pathway of tumorigenesis (Ohmura et al, 2000). Thus, the presence of p53 mutation/overexpression and microsatellite alteration clearly discriminated Ca-NIN tumors from L-NIN and H-NIN tumors, supporting the credibility of the Padova international classification (Rugge et al, 2000). hMLH1 inactivation by promoter hypermethylation is the major causative event in the mutator pathway of gastric carcinogenesis (Bevilacqua and Simpson, 2000; Fleisher et al, 1999, 2001; Kang et al, 1999). In this study we observed that all cases with a lack of hMLH1 protein expression also exhibited $\mathrm{MSI}-\mathrm{H}$. Therefore, in practice, immunohistochemical staining for p53 and hMLH1 may allow the discrimination of Ca-NIN from L-NIN and H-NIN tumors. In addition, detection of either p53 or hMLH1 abnormalities may aid therapeutic decisions because abnormal expression of these proteins can serve as markers for the suppressor and mutator pathways in carcinogenesis, which are known to exhibit different

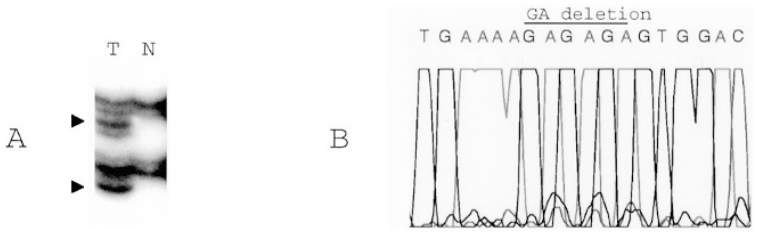

Figure 2.

Mutation analysis of exon 15 of the APC gene. A, PCR-single strand conformation polymorphism (PCR-SSCP) analysis shows shift bands (arrowheads) in case 19. B, Sequencing analysis of the mobility-shift bands reveals GA deletion at codons 1462 to 1464 of the APC gene in case 19. T, tumor DNA; $N$, normal DNA. 
Table 2. Sequence Alterations of $p 53$ and $A P C$ in Gastric Noninvasive Neoplasia

\begin{tabular}{ccll}
\hline Case & Exon & Codon & \multicolumn{1}{c}{ Nucleotide change } \\
\hline $\begin{array}{c}\text { P53 } \\
\text { Ca-NIN }\end{array}$ & & \\
32 & 7 & 245 & GGC (Gly) $\rightarrow$ AGC (Ser) \\
36 & 7 & 245 & GGC (Gly) $\rightarrow$ AGC (Ser) \\
38 & 7 & 245 & GGC (Gly) $\rightarrow$ AGC (Ser) \\
45 & 5 & 158 & CGC (Arg) $\rightarrow$ CAC (His) \\
48 & 5 & 146 & TGG (Trp) $\rightarrow$ TAG (stop) \\
APC & & & \\
L-NIN & 15 & $1462-1464$ & GAGA deletion (frame shift) \\
4 & 15 & $1462-1464$ & GAGA deletion (frame shift) \\
5 & 15 & $1462-1464$ & GAGA deletion (frame shift) \\
6 & 15 & $1462-1464$ & GA deletion (frame shift) \\
9 & 15 & $1462-1464$ & GA deletion (frame shift) \\
10 & 15 & $1462-1464$ & GAGA deletion (frame shift) \\
11 & 15 & $1462-1464$ & GA deletion (frame shift) \\
19 & & & \\
H-NIN & 15 & $1462-1464$ & GAGA deletion (frame shift) \\
27 & 15 & $1462-1464$ & GA deletion (frame shift) \\
28 & 15 & $1319-1322$ & TGTGAGCGAG deletion (frame shift) \\
Ca-NIN & 15 & $1462-1464$ & GA deletion (frame shift) \\
49 & & & \\
\hline 6 & & & \\
\hline
\end{tabular}

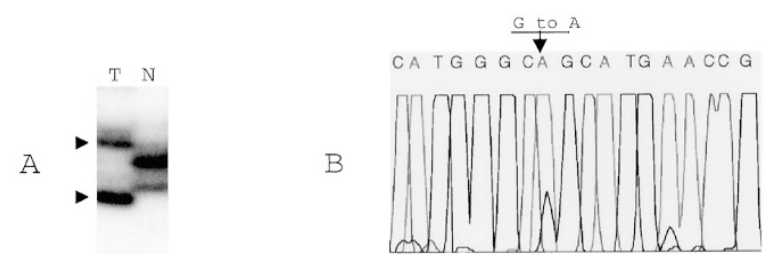

Figure 3.

Mutation analysis of exon 7 of the $p 53$ gene. A, PCR-SSCP analysis shows shift bands (arrowheads) in case 36. B, Sequencing analysis of the mobility-shift bands shows a missense mutation at codon 245 of the $p 53$ gene in case 36 . $T$, tumor DNA; $N$, normal DNA.

biologic behaviors. For example, tumors that follow the mutator pathway have less frequent lymph node metastasis and a more favorable prognoses (Wu et al, 2000; Yamamoto et al, 1999).

Although there is still uncertainty regarding the malignant potential of L-NIN and H-NIN tumors, tumors that roughly correspond to gastric adenoma, it has been argued that the sequential progression of L-NIN and H-NIN to Ca-NIN (ie, an adenomacarcinoma sequence in gastric epithelium) does not occur (Tamura, 1996; Tamura et al, 1996a). However, because of the widely varying reported incidences of genetic alterations in gastric adenoma/dysplasia resulting from differences in the histopathologic criteria used (as described above), the incidence of diagnosis of "carcinoma in adenoma" may also have been affected (Kim et al, 2000, 2001). Because the occurrence of two or more histopathologic subtypes exhibiting different degrees of cellular and structural atypia is common within gastric cancers, "carcinoma in adenoma" would perhaps have been diagnosed as "car-

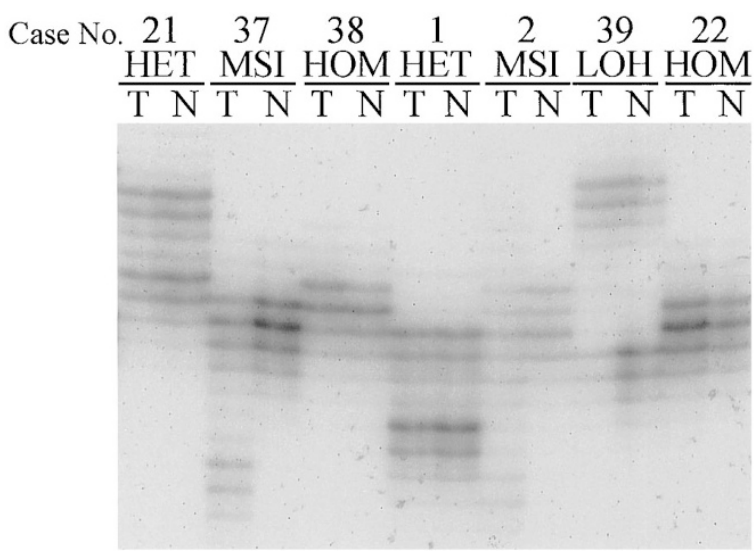

Figure 4.

A representative illustration of microsatellite analysis at TP53. Alterations are judged as microsatellite instability (MSI) when additional bands that are not seen in the corresponding normal DNA appear in the tumor DNA (cases 37 and 2) and as loss of heterozygosity (LOH) when a band corresponding to one allele of the normal DNA is lost in the tumor DNA (case 39). T, tumor DNA; N, normal DNA; HET, heterozygosity; HOM, homozygosity.

cinoma in carcinoma" using different histopathologic criteria. In an analysis of 103 differentiated-type gastric carcinomas less than $5 \mathrm{~mm}$ in diameter, there was no evidence of associated adenoma; in fact, intestinal metaplasia, especially incomplete intestinal metaplasia, was the common ancillary finding (Sasaki et al, 1999). Indeed, the reported incidence of $\mathrm{LOH}$ in the adenomatous component of carcinoma in adenoma was $87 \%$ (Kim et al, 2001), which is higher than our results for Ca-NIN tumors (61\%), although different microsatellite markers were used in those studies.

Cellular phenotype, as defined by mucin histochemistry and immunohistochemistry, may be another 


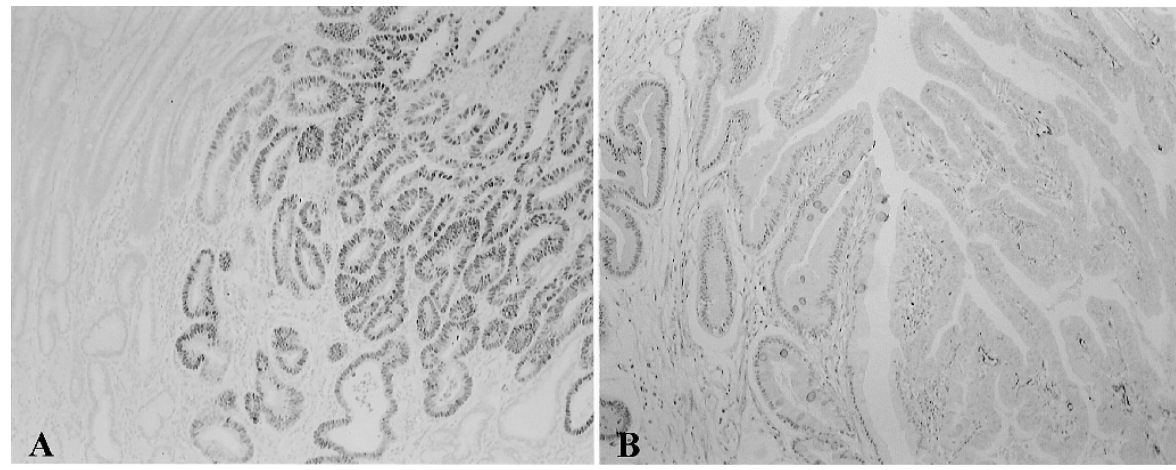

Figure 5.

Immunohistochemical analysis of p53 and hMLH1 protein expression. A, Nuclear accumulation of p53 protein in case 45 (original magnification, $\times 100$ ). B, Reduction of hMLH1 protein expression (right) in case 52 (original magnification, $\times 100$ ).

Table 3. Relationship of Histology and Expression Pattern of p53 and hMLH1 in Gastric Noninvasive Neoplasia

\begin{tabular}{cccc}
\hline Histology & $\mathrm{p} 53+/ \mathrm{hMLH} 1+(\%)^{a}$ & $\mathrm{p} 53-/ \mathrm{hMLH} 1-(\%)^{b}$ & $\mathrm{p} 53-/ \mathrm{hMLH} 1+(\%)^{c}$ \\
\hline L-NIN $(n=20)$ & $0(0 \%)$ & $1(5 \%)$ & $19(95 \%)$ \\
H-NIN $(n=9)$ & $1(11 \%)$ & $0(0 \%)$ & $8(89 \%)$ \\
Ca-NIN $(n=23)$ & $10(44 \%)$ & $6(26 \%)$ & $7(30 \%)$ \\
\hline
\end{tabular}

${ }^{a}$ L-NIN/H-NIN vs Ca-NINN, $p<0.001$ (Fisher's exact test).

${ }^{b} \mathrm{~L}-\mathrm{NIN} / \mathrm{H}-\mathrm{NIN}$ vs Ca-NIN, $p=0.017$ (Fisher's exact test).

${ }^{c}$ L-NIN/H-NIN vs Ca-NIN, $p<0.001$ (Fisher's exact test).

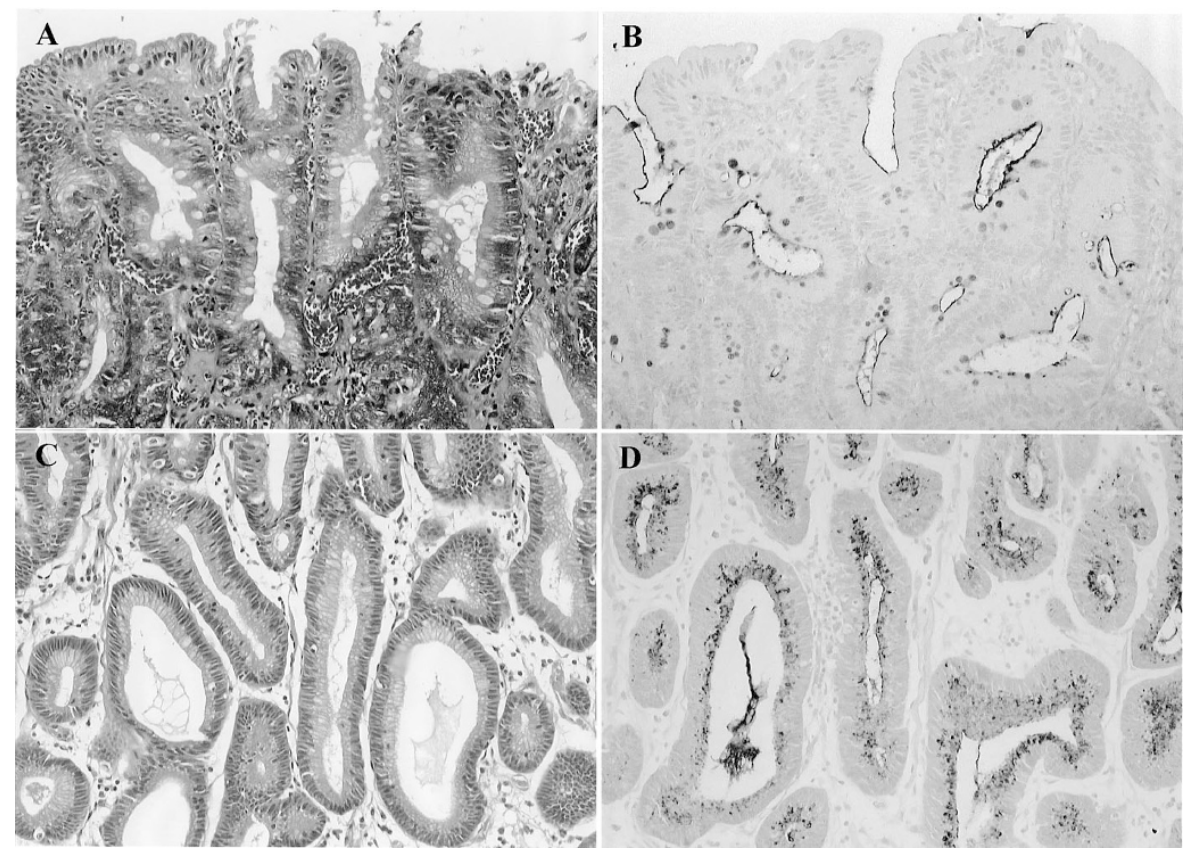

Figure 6.

Cellular phenotypic analysis. A, The neoplastic lesion closely mimics the features of complete-type intestinal metaplasia (case 10, original magnification, $\times 200$ ). B, Brush borders of neoplastic cells are strongly positive for CD10 (case 10, original magnification, $\times 200$ ). C. The neoplastic lesion mimics the features of gastric foveolar epithelium (case 2, original magnification, $\times 200$ ). D, The neoplastic cells are diffusely positive for 45M1 (case 2, original magnification, $\times 200$ ).

promising area in the search for markers of malignant potential in gastric noninvasive neoplasia. Although conventional gastric adenomas usually have a predominantly intestinal, or complete intestinal phenotype, attention should also be paid to so-called "gastric-type adenoma" (Kushima et al, 1996). The great majority of gastric cancers display variable de- grees of mixed gastric and intestinal cellular phenotypes, with the foveolar- and CIM-type carcinomas constituting less than $10 \%$ of all early differentiated adenocarcinomas. Moreover, a strong association has been shown between the cellular phenotype and specific genetic pathways (Ohmura et al, 2000). Thus, intestinal- and gastric-type adenomas may follow dif- 
ferent genetic pathways. In the present study, 52 gastric NIN tumors were investigated using a combination of mucin-histochemistry and mucinimmunohistochemistry. Using our strict definition of cellular phenotype (Ohmura et al, 2000), we found that the frequency of a CIM-type was significantly higher in L-NIN cases (35\%) than in Ca-NIN $(4 \%)(p<0.01)$ cases. A long-term follow-up study of gastric adenomas reported that malignant transformation occurred more frequently when the adenomas were comprised of mixed gastric and intestinal phenotypes rather than solely an intestinal phenotype (Kolodziejczyk et al, 1994). This has led to the hypothesis that the presence of gastric phenotype within the adenoma portends a risk of malignant transformation via the mutator pathway (Endoh et al, 2000b). Despite the fact that the cellular phenotype tends to progress from a gastric to an intestinal phenotype as the tumor evolves (Tatematsu et al, 1992), the CIM-type was more frequently observed in L-NIN than in Ca-NIN tumors in the present study. These findings lend support to our contention that CIM-type adenomas may only rarely undergo malignant transformation.

In conclusion, the Padova international classification correlated with both the molecular and cellular phenotypic profiles and should therefore be more widely used in the classification of noninvasive gastric neoplasia. In practice, immunohistochemical staining for p53 and hMLH1 proteins may be a simple and useful tool to discriminate between Ca-NIN and L-NIN and $\mathrm{H}-\mathrm{NIN}$ tumors.

\section{Materials and Methods}

\section{Samples}

A total of 52 gastric noninvasive tumors were examined in this study. Thirty-five of the specimens were obtained using standard surgical resections and 17 were obtained by endoscopic mucosal resection of the tumors, from 52 patients. All specimens were diagnosed histopathologically as either gastric adenoma or noninvasive adenocarcinoma with tubular differentiation, at the Department of Pathology, Yamagata University School of Medicine between 1998 and 2000. Tumors were then reclassified according to the Padova international classification (Rugge et al, 2000) by two of the authors (ZJ and GT) as 20 cases of L-NIN, 9 of H-NIN, and 23 of Ca-NIN (Fig. 1). In tumors with interobserver variability, consensus was made after discussion. Tumor and corresponding normal DNAs were extracted according to the method described previously (Ohmura et al, 2000). The clinicopathologic characteristics are summarized in Table 1.

\section{PCR-Single Strand Conformation Polymorphism (PCR-SSCP) and Sequencing Analyses}

PCR-SSCP analyses of exons 5, 6, 7, and 8 of the p53 gene and codons 1274 to 1523 in exon 15 of the $A P C$ gene were performed using published primer sequences and conditions (Tamura et al, 1995; Yagi et al, 1997). Shifted bands detected by SSCP were excised from the gels and subjected to a second round of PCR amplification using the same primers as used in the primary PCR. The resultant PCR products were purified and sequenced using the dRhodamine Terminator Cycle Sequencing FS Ready Reaction Kit (PE Applied Biosystems, Foster City, California) and an automated DNA sequencer (ABI PRISM 310; PE Applied Biosystems).

\section{Microsatellite Analysis}

PCR primers for microsatellite markers were obtained from Research Genetics (Huntsville, Alabama). Microsatellite markers were selected to cover chromosomal regions frequently deleted in gastric carcinomas (Nishizuka et al, 1998; Tamura et al, 1996b). The following 12 primer pairs were used: D2S115 (2q), D4S404 (4p), D5S178 (5q), IL9 (5q), D6S265 (6p), D7S490 (7q), D11S900 (11q), MYH6 (14q), TP53 (17p), D17S1176 (17p), D18S46 (18q), and D21S1407 (21q). A marker for the mononucleotide repeat BAT-26 (2q) (Research Genetics), highly sensitive for MSI, was also used. PCR was performed as described previously (Tamura et al, 1996b). PCR products were separated on $6 \%$ denaturing polyacrylamide gels. Assessment of $\mathrm{LOH}$ and $\mathrm{MSI}$ was also described previously (Tamura et al, 1996b). Samples were defined as MSI-H if more than $30 \%$ of the loci observed were unstable, MSI-L if less than $30 \%$ of loci were unstable, and MSS if no unstable loci were observed (Boland et al, 1998).

\section{Analysis of p53 and hMLH1 Protein Expression by Immunohistochemistry}

Immunostaining for $\mathrm{p} 53$ and $\mathrm{hMLH} 1$ proteins was performed using the mAbs Pab 1801 (Novocastra, New Castle, United Kingdom) (1:40 dilution) and G168-728 (PharMingen, San Diego, California) (1:50 dilution), respectively, using a standard labeled streptavidin-biotin system (Nichirei, Tokyo, Japan).

\section{Cellular Phenotypic Analysis}

Sections from one or two representative paraffin blocks were stained with hematoxylin and eosin. In addition, the following histochemical and immunohistochemical staining was also performed: galactose oxidase-Schiff (GOS), paradoxical ConA, immunostaining with mAb 45M1 (Novocastra) (Bara et al, 1991), immunostaining with MUC 2 mAb (Novocastra) (Tytgat et al, 1994), and immunostaining with CD10 mAb (Novocastra) (Danielsen et al, 1980). Galactose oxidase-Schiff and 45M1 were used to detect gastric foveolar mucin, ConA to detect pyloric-gland cells and mucous neck cells, MUC 2 to detect intestinal gobletcell mucin, and CD10 to detect brush borders in complete-type intestinal metaplasia. Immunohistochemical staining was performed on formalin-fixed, paraffin-embedded sections using standard labeled streptavidin-biotin methods (Nichirei). Cellular phenotypes for the 52 gastric noninvasive tumors were defined as outlined previously (Ohmura et al, 2000). All specimens that were subject to histochemical and 
immunohistochemical staining were evaluated by two pathologists.

\section{Statistical Analysis}

Statistical analysis was performed using Fisher's exact probability test. A $p$ value of less than 0.05 was considered to be statistically significant.

\section{References}

Bara J, Gautier R, Mouradian P, Decaens C, and Daher N (1991). Oncofetal mucin M1 epitope family: Characterization and expression during colonic carcinogenesis. Int $\mathrm{J}$ Cancer 47:304-310.

Bevilacqua RA and Simpson AJ (2000). Methylation of the $\mathrm{hMLH} 1$ promoter but no hMLH1 mutations in sporadic gastric carcinomas with high-level microsatellite instability. Int $\mathrm{J}$ Cancer 87:200-203.

Boland CR, Thibodeau SN, Hamilton SR, Sidransky D, Eshleman JR, Burt RW, Meltzer SJ, Rodriguez-Bigas MA, Fodde R, Ranzani GN, and Srivastava S (1998). A National Cancer Institute Workshop on Microsatellite Instability for cancer detection and familial predisposition: Development of international criteria for the determination of microsatellite instability in colorectal cancer. Cancer Res 58:5248-5257.

Craanen ME, Blok P, Dekker W, Offerhaus GJ, and Tytgat GN (1995). Chronology of p53 protein accumulation in gastric carcinogenesis. Gut 36:848-852.

Danielsen EM, Vyas JP, and Kenny AJ (1980). A neutral endopeptidase in the microvillar membrane of pig intestine: Partial purification and properties. Biochem J 191:645-648.

Endoh Y, Sakata K, Tamura G, Ohmura K, Ajioka Y, Watanabe $\mathrm{H}$, and Motoyama T (2000a). Cellular phenotypes of differentiated-type adenocarcinomas and precancerous lesions of the stomach are dependent on the genetic pathways. J Pathol 191:257-263.

Endoh Y, Tamura G, Ajioka Y, Watanabe H, and Motoyama T (2000b). Frequent hypermethylation of the hMLH1 gene promoter in differentiated-type tumors of the stomach with the gastric foveolar phenotype. Am J Pathol 157:717-722.

Fleisher AS, Esteller M, Tamura G, Rashid A, Stine OC, Yin J, Zou TT, Abraham JM, Kong D, Nishizuka S, James SP, Wilson KT, Herman JG, and Meltzer SJ (2001). Hypermethylation of the hMLH1 gene promoter is associated with microsatellite instability in early human gastric neoplasia. Oncogene 20:329-335.

Fleisher AS, Esteller M, Wang S, Tamura G, Suzuki H, Yin J, Zou TT, Abraham JM, Kong D, Smolinski KN, Shi YQ, Rhyu MG, Powell SM, James SP, Wilson KT, Herman JG, and Meltzer SJ (1999). Hypermethylation of the hMLH1 gene promoter in human gastric cancers with microsatellite instability. Cancer Res 59:1090-1095.

Horii A, Nakatsuru S, Miyoshi Y, Ichii S, Nagase H, Kato Y, Yanagisawa A, and Nakamura $Y$ (1992). The APC gene, responsible for familial adenomatous polyposis, is mutated in human gastric cancer. Cancer Res 52:3231-3233.

Isozaki H, Tanaka N, and Okajima K (1999). General and specific prognostic factors of early gastric carcinoma treated with curative surgery. Hepatogastroenterology 46:18001808.
Joypaul BV, Newman EL, Hopwood D, Grant A, Qureshi S, Lane DP, and Cuschieri A (1993). Expression of p53 protein in normal, dysplastic, and malignant gastric mucosa: An immunohistochemical study. J Pathol 170:279-283.

Kamiya T, Morishita T, Asakura H, Miura S, Munakata Y, and Tsuchiya M (1982). Long-term follow-up study on gastric adenoma and its relation to gastric protruded carcinoma. Cancer 50:2496-2503.

Kang GH, Shim YH, and Ro JY (1999). Correlation of methylation of the hMLH1 promoter with lack of expression of $\mathrm{hMLH} 1$ in sporadic gastric carcinomas with replication error. Lab Invest 79:903-909.

Kim HS, Woo DK, Bae SI, Kim YI, and Kim WH (2000). Microsatellite instability in the adenoma-carcinoma sequence of the stomach. Lab Invest 80:57-64.

Kim HS, Woo DK, Bae SI, Kim YI, and Kim WH (2001). Allelotype of the adenoma-carcinoma sequence of the stomach. Cancer Detect Prev 25:237-244.

Kolodziejczyk P, Yao T, Oya M, Nakamura S, Utsunomiya T, Ishikawa T, and Tsuneyoshi M (1994). Long-term follow-up study of patients with gastric adenomas with malignant transformation: An immunohistochemical and histochemical analysis. Cancer 74:2896-2907.

Kushima R, Muller W, Stolte M, and Borchard F (1996). Differential p53 protein expression in stomach adenomas of gastric and intestinal phenotypes: Possible sequences of p53 alteration in stomach carcinogenesis. Virchows Arch 428: 223-227.

Kyokane $\mathrm{K}$, Ito $\mathrm{M}$, Sato $\mathrm{Y}$, Ina $\mathrm{K}$, Ando $\mathrm{T}$, and Kusugami $\mathrm{K}$ (1998). Expression of $\mathrm{Bcl}-2$ and p53 correlates with the morphology of gastric neoplasia. J Pathol 184:382-389.

Maesawa C, Tamura G, Suzuki Y, Ogasawara S, Sakata K, Kashiwaba M, and Satodate R (1995). The sequential accumulation of genetic alterations characteristic of the colorectal adenoma-carcinoma sequence does not occur between gastric adenoma and adenocarcinoma. J Pathol 176:249-258.

Nakamura K, Sakaguchi H, and Enjoji M (1988). Depressed adenoma of the stomach. Cancer 62:2197-2202.

Nakatsuru S, Yanagisawa A, Ichii S, Tahara E, Kato Y, Nakamura Y, and Horii A (1992). Somatic mutation of the APC gene in gastric cancer: Frequent mutations in very well differentiated adenocarcinoma and signet-ring cell carcinoma. Hum Mol Genet 1:559-563.

Nishizuka S, Tamura G, Terashima M, and Satodate R (1998). Loss of heterozygosity during the development and progression of differentiated adenocarcinoma of the stomach. J Pathol 185:38-43.

Ogasawara S, Maesawa C, Tamura G, and Satodate R (1994). Lack of mutations of the adenomatous polyposis coli gene in oesophageal and gastric carcinomas. Virchows Arch 424:607-611.

Ohmura K, Tamura G, Endoh Y, Sakata K, Takahashi T, and Motoyama T (2000). Microsatellite alterations in differentiated-type adenocarcinomas and precancerous lesions of the stomach with special reference to cellular phenotype. Hum Pathol 31:1031-1035.

Powell SM, Cummings OW, Mullen JA, Asghar A, Fuga G, Piva P, Minacci C, Megha T, Tosi P, and Jackson CE (1996). Characterization of the APC gene in sporadic gastric adenocarcinomas. Oncogene 12:1953-1959. 
Ranzani GN, Renault B, Pellegata NS, Fattorini P, Magni E, Bacci F, and Amadori D (1993). Loss of heterozygosity and K-ras gene mutations in gastric cancer. Hum Genet 92:244249.

Riddell RH and Iwafuchi M (1998). Problems arising from Eastern and Western classification systems for gastrointestinal dysplasia and carcinoma: Are they resolvable? Histopathology 33:197-202.

Rugge M, Correa P, Dixon MF, Hattori T, Leandro G, Lewin K, Riddell RH, Sipponen P, and Watanabe H (2000). Gastric dysplasia: The Padova international classification. Am J Surg Pathol 24:167-176.

Sasaki I, Yao T, Nawata H, and Tsuneyoshi M (1999). Minute gastric carcinoma of differentiated type with special reference to the significance of intestinal metaplasia, proliferative zone, and p53 protein during tumor development. Cancer 85:1719-1729.

Sasako M (2000). What is reasonable treatment for gastric adenocarcinoma? J Gastroenterol 35(Suppl 12):116-120.

Schlemper RJ, Itabashi M, Kato Y, Lewin KJ, Riddell RH, Shimoda T, Sipponen P, Stolte M, Watanabe H, Takahashi H, and Fujita R (1997). Differences in diagnostic criteria for gastric carcinoma between Japanese and western pathologists. Lancet 349:1725-1729.

Schlemper RJ, Riddell RH, Kato Y, Borchard F, Cooper HS, Dawsey SM, Dixon MF, Fenoglio-Preiser CM, Flejou JF, Geboes K, Hattori T, Hirota T, Itabashi M, Iwafuchi M, Iwashita A, Kim YI, Kirchner T, Klimpfinger M, Koike M, Lauwers GY, Lewin KJ, Oberhuber G, Offner F, Price AB, Rubio CA, Shimizu M, Shimoda T, Sipponen P, Solcia E, Stolte M, Watanabe H, and Yamabe H (2000). The Vienna classification of gastrointestinal epithelial neoplasia. Gut 47: 251-255.

Semba S, Yokozaki H, Yamamoto S, Yasui W, and Tahara E (1996). Microsatellite instability in precancerous lesions and adenocarcinomas of the stomach. Cancer 77(8 Suppl):16201627.

Tamura G (1996). Molecular pathogenesis of adenoma and differentiated adenocarcinoma of the stomach. Pathol Int 46:834-841.
Tamura G, Maesawa C, and Satodate R (1996a). Author's reply. J Pathol 178:476.

Tamura G, Sakata K, Maesawa C, Suzuki Y, Terashima M, Satoh K, Sekiyama S, Suzuki A, Eda Y, and Satodate R (1995). Microsatellite alterations in adenoma and differentiated adenocarcinoma of the stomach. Cancer Res 55:19331936.

Tamura G, Sakata K, Nishizuka S, Maesawa C, Suzuki Y, Terashima M, Eda Y, and Satodate R (1996b). Allelotype of adenoma and differentiated adenocarcinoma of the stomach. J Pathol 180:371-377.

Tatematsu M, Hasegawa R, Ogawa K, Kato T, Ichinose M, Miki K, and Ito N (1992). Histogenesis of human stomach cancers based on assessment of differentiation. J Clin Gastroenterol 14(Suppl 1):S1-7.

Tohdo H, Yokozaki H, Haruma K, Kajiyama G, and Tahara E (1993). p53 gene mutations in gastric adenomas. Virchows Arch B Cell Pathol Incl Mol Pathol 63:191-195.

Tytgat KM, Buller HA, Opdam FJ, Kim YS, Einerhand AW, and Dekker J (1994). Biosynthesis of human colonic mucin: Muc2 is the prominent secretory mucin. Gastroenterology 107:1352-1363.

Wu MS, Lee CW, Shun CT, Wang HP, Lee WJ, Chang MC, Sheu JC, and Lin JT (2000). Distinct clinicopathologic and genetic profiles in sporadic gastric cancer with different mutator phenotypes. Genes Chromosomes Cancer 27:403411.

Yagi OK, Akiyama Y, Ohkura Y, Ban S, Endo M, Saitoh K, and Yuasa Y (1997). Analyses of the APC and TGF-beta type II receptor genes, and microsatellite instability in mucosal colorectal carcinomas. Jpn J Cancer Res 88:718-724.

Yamamoto H, Perez-Piteira J, Yoshida T, Terada M, Itoh F, Imai K, and Perucho M (1999). Gastric cancers of the microsatellite mutator phenotype display characteristic genetic and clinical features. Gastroenterology 116:1348-1357. 